\title{
A Study of the Relationship between Persian and English Writing Skills among Adult EFL Learners in Iran
}

\author{
Azim Javadi-Safa, M.A. In TEFL (Corresponding Author) \\ Payame Noor University \\ Faculty of Literature and Humanities, Payame Noor University \\ Postal Code: 41938-1957, Rasht, Iran \\ Tel: 0098-911-135-1806 E-mail: a_javadisafa@yahoo.com \\ Fereidoon Vahdany, Ph.D. In TEFL \\ Payame Noor University \\ Department of English, Payame Noor University \\ Postal Code: 41938-1957, Rasht, Iran \\ Masoud Khalili Sabet, Ph.D. In TEFL \\ Guilan University \\ Faculty of Literature and Humanities, The University of Guilan \\ Postal Code: 41635-3988, Rasht, Iran
}

Received: 25-11- 2012

Accepted: 24-12- 2012

Published: 01-03- 2013

doi:10.7575/aiac.ijalel.v.2n.2p.43

URL: http://dx.doi.org/10.7575/aiac.ijalel.v.2n.2p.43

\begin{abstract}
This research aims at investigating the relationship between writing skill and sub-skills of first language (Persian) and foreign language (English). Therefore, 50 upper-intermediate EFL learners in Iran who were majoring in the English language were asked to write on two different topics in Persian and English. Then, the compositions were evaluated based on ESL Composition Profile. Subsequently, using Pearson product-moment correlation, the correlation between the compositions overall scores in L1 and L2, as well as the correlations between each of five major components of writing, including content, organization, vocabulary, language use, and mechanics in the two languages were examined. The results displayed large correlations between the compositions overall scores as well as between the four writing sub-skills in L1 and L2. The highest correlations were observed between writing sub-skills of vocabulary, mechanics, language use, and content respectively. These findings entail some pedagogical implications for effective language learning in both L1 and L2, utilizing the enhancing effect of cross-linguistic transfer of writing.
\end{abstract}

Key words: L1-L2 Relationship, Cross-linguistic Transfer, Writing, Adult EFL Learners, Persian

\section{Introduction}

The importance of writing skill and its prominent role in demonstrating students' learning magnitude is undeniable be it writing in the first or the second language. Academics most preferably evaluate students through their writing. Hence, poor writing ability of students may jeopardize their academic success to a considerable extent (Tan, 2011). However, it is much more daunting for non-natives, especially EFL learners in Iran with only limited exposure to English. Therefore, any study that could shed some light on the nature of writing skills and facilitates their learning, especially in a foreign language, would be of great benefit to all stakeholders in the field of language.

One the other hand, the Linguistic Interdependence Hypothesis of Cummins $(1979,1991)$ assumes that when a language operation such as writing has been acquired in one language, the same operation is not acquired again in another language, but is simply applied in the second language. Consequently, proficiency in one language might promote development of proficiency in a second language, particularly with respect to literacy related skills that involve concept knowledge generally acquired at school settings (Arefi, 1997). Hence, this area of research, named as crosslinguistic influence, calls for more attention by enthusiastic researchers since it seems more economical to drawn on previously learned items for learning new ones rather than starting from scratch. However, surprisingly, teaching for cross language transfer has not yet received its due attention in designing courses and materials for language learners.

In conclusion, studies investigating the relationship between writing skills and sub-skills of first and foreign language, especially those attesting the transfer of writing skills between L1 and L2, could be breakthrough in encouraging and guiding curriculum designers and material developers to design language courses, having cross language transfer issue in mind. 


\subsection{Review of Literature}

The role of first language knowledge and its influence on second language acquisition, as an important issue in the field of language, has occupied researchers for the last few decades. A couple of theories and hypotheses have gradually contributed to shaping the contemporary knowledge on the relationship between learners' languages. However, speculation about the direct effect of L1 on L2 mainly emanated from Linguistic Interdependence Hypothesis (LIH). In this hypothesis, Cummins (1979, p. 233) proposed that "language skills will transfer from L1 to L2 if there is sufficient exposure to the L2 and motivation to learn the language." According to Cummins (1984), there is an "underlying cognitive/ academic proficiency," which is common or interdependent across languages and allows for the cognitive/academic or literacy related skills to be transferred across them. The term language transfer is defined as "the impact of one's knowledge in one language on learning or performing in another language" (Figueredo, 2006, as cited in Joy, 2011). Although this notion as a noteworthy variable that affects the learning of a second or foreign language has been widely researched, there is still no consensus among scientists on its definition (Agustin Llach, 2010). It is also worth mentioning that the terms cross-linguistic influence and language transfer have long been drawn on by researchers interchangeably (Odlin, 2005).

Studies on the relationship between first and second language goes back to 1980s and early 1990s from L1 and L2 educators. However, during 1950s and 1690s educators had already designed aptitude tests for predicting the degree of success in second language learning which was evaluated through first language measures such as vocabulary, soundsymbol relationships, grammatical concepts, and verbal memory (Sparks, Patton, Ganschow \& Humbach, 2009). More specifically, studies of cross-linguistic influence in writing can be studied in the realm of Contrastive Rhetoric (CR) by Kaplan (1966) whose main concern seems to heavily rest on the very basic notion of cultural differences and variations, which is in turn, reflected in learners' writing (Derakhshan,1996). In a more recent account of the term, Connor (1996) defines contrastive rhetoric as "an area of research in second language acquisition that identifies problems in composition faced by second language writers, and, by referring to the rhetorical strategies of the first language, attempts to explain them" (p. 5).

According to Silva (1993, p.657, as cited in Blackmore-Squires, 2010) there are similarities between L1 an L2 writing at superficial levels as well as between the processes that L1 and L2 writers go through. In addition, Zamel (1984), based on the results of her study, suggested that "L2 composing processes indicate that the L1 process-orientated writing instruction might also be effective for teaching L2 writing" (p. 198). However, Raimes (1985) raised doubts about the applicability of L1 composition pedagogy to L2 classrooms and displayed that there are differences in their processing.

It is also worth mentioning that although transfer studies have been conducted at both oral and written levels, written transfer has been of major interest among most researchers in recent studies. For instance, Dweik and Abu Al Hommos (2007) reported the positive transfer of writing skills of intermediate Arabic-English bilinguals in Jordan through examining their compositions in the two languages. Similarly, Alsamadani (2010) investigated the relationship between Saudi EFL learners' writing proficiency in L1 (Arabic) and L2 (English). He examined the college level participants' argumentative compositions in both languages and found a strong correlation between them. On the other hand, Carson, Carrell, Silberstein, Kroll, and Kuehn (1990) investigated Japanese and Chinese ESL students and found only weak to moderate correlations between L1 and L2 writing abilities. In the case of Japanese ESL learners, L1 and L2 writing scores showed weak correlation and for the Chinese students was not significant.

In order to investigate the transfer of writing skills between Persian and English (as two languages that do not share the same writing features, grammar, graphic conventions, or even the same type of writing system) few research has been done. Studies conducted by Arefi (1997), and Zia Houseini and Derakhshan (2006) are two cases in point.

Arefi (1997) studied the relationship between first and second language writing skills for Iranian students in Australia. In this respect, the students were asked to write descriptive and comparative essays in English and Persian. Then, their papers were evaluated using three writing indicators, including "linguistic productivity," "holistic scheme," and "technical skills." In her study, linguistic productivity consisted of number of words, number of simple sentences, number of complex sentences, T-units, and mean T-unit length in students' essays. Holistic scheme was assessed through the number of ideas introduced by the subject, the development of ideas, coherence, the connection between ideas, and the ending. Technical skills consisted of spelling, punctuation, grammatical correctness (knowledge of vocabulary and rules of word formation, spelling, and sentence formation), and capitalization. Finally, the results of Arefi's study (1997) displayed that L1 (Persian) writing skill indicators of linguistic productivity and holistic scheme transferred to the English language despite the very different writing system of these two languages. Furthermore, in spite of no apparent transfer of technical writing skills from L1 to L2, she found a positive correlation between the technical skills of the bilingual children under the study and their length of residence in Australia. Consequently, Arefi (1997) concluded that this suggested that "a longer exposure to the language itself and the impact of schooling is important in developing technical skills."

In another research, which seems to be the most related research to the current study, Zia Houseini and Derakhshan (2006) investigated the relationship between first language (Persian) and foreign language (English) writing skill of Iranian college-level students who were majoring in English. Hence, the students were asked to write narrative and argumentative compositions in L1 and L2, and then, the compositions were evaluated based on ESL Composition Profile. As a result, they concluded the existence of a significant relationship between Persian and English writing tasks. 
Moreover, they displayed that there is a systematic difference between the performances of this group of students in L1 and L2 writing tasks, which pointed in the direction of transfer from L1 (Persian) to L2 (English).

However, in Zia Houseini and Derakhshan's (20006) research, the differences between mean performances of writing in Persian and English were not very large and the correlation coefficient of writing argumentative (but not narrative) compositions in Persian and English was only moderately significant. On the other hand, the participants of this study wrote the compositions at home, which might cause some maturation problems and put the internal validity of the testing measure under question. Accordingly, further research is required to replicate the study and confirm its findings to be able to make strong claims on this issue.

Furthermore, Zia Houseini and Derakhshan's (2006) study has not investigated the transfer of each of major writing components of content, organization, vocabulary, language use, and mechanics separately. Actually, it examined the overall scores of compositions to investigate the transfer issue, and even in this case, it has not taken into account the role of writing technical skills (mechanics of writing and grammatical correctness) in evaluating the compositions overall scores.

In addition, Although Arefi (1997) has already demonstrated that Persian writing technical skills of Iranian bilingual children studying in an English-medium country would not transfer to their English writing; further research is required in order to investigate the feasibility of such a transfer in an EFL context for adult learners.

In conclusion, the significance of conducting this research is in considering comprehensive criteria for evaluating writing proficiency, through taking account of all major components of ESL Composition Profile (Jacobs, Zinkgraf, Wormuth, Hartfiel, \& Hughey, 1981), in order to investigate the transfer of writing skill, especially in an EFL setting. Furthermore, the novelty value of this research is in investigating the transfer of each of five major components of ESL Composition Profile, including content, organization, vocabulary, language use, and mechanics separately, which have not yet been examined in similar studies.

\subsection{Research Questions and Hypotheses}

The present study aims at finding whether there is a cross-linguistic transfer in writing skills of the Persian students studying English in Iran. Thus, in line with the literature reviewed above, it adopts a quantitative method to answer the following research questions:

1. Is there a significant relationship between Iranian upper-intermediate language learners' overall proficiency in foreign language (English) writing skills and their first language (Persian) writing skills?

2. Is there a significant relationship between Iranian upper-intermediate language learners' proficiency in each of foreign language writing sub-skills (i.e. five major components of content, organization, vocabulary, language use, and mechanics) and their corresponding first language writing sub-skills?

According to the aforementioned research questions, the following null hypotheses have been formulated:

Ho.1 There is no significant correlation between first language and foreign language overall writing skills of Iranian upper-intermediate language learners.

Ho.2 There is no significant correlations between each of first language writing sub-skills and their corresponding writing sub-skills in English of Iranian upper-intermediate language learners.

\section{Methodology}

\subsection{Introduction}

The current study is conducted in the academic year of 2011-2012 at the English departments of Guilan University and Payame Noor University in Iran. It aims at investigating whether there is a relationship between first language (Persian) and foreign language (English) writing skills of adult EFL learners at upper-intermediate level. This section addresses the methodology and the procedures of the study. In this respect, it presents detailed information regarding the participants and their selection procedure, the instruments, the data collection and the data analysis used in the study.

\subsection{Participants}

\subsubsection{Raters}

Four expert raters were employed to evaluate the subjects' compositions; two experienced high school teachers of Persian language who hold M.A. in Persian literature, for evaluating the Persian compositions, and two qualified English language teachers at M.A. level for rating the English compositions. The raters were all males and their age ranged from 29 to 45 . They did not have any familiarity with the students (and the papers were also blind-coded) in order to have objective ratings.

\subsubsection{Students}

In total, eighty-seven university students (33 males, 54 females) who were majoring in the English language in Guilan University and Payame Noor University participated in this study. They all were studying at BA level and they all have already passed at least one course in English writing. Their age ranged from 18 to 27, and they were chosen from three intact classes which the researcher had access to. In order to ensure the homogeneity of the participants' proficiency level, a version of Oxford Placement Test (OPT) was administered to all the students who voluntarily participated in this exam. 
Then, based on the result of OPT, 50 upper-intermediate students (18 males, 32 females) were selected through simple random sampling for this study $(\mathrm{n}=50)$. Their age ranged from 18 to 24 .

At last, it is worth noting the reasons for choosing upper-intermediate level. First, based on Linguistic Threshold Hypothesis of Cummins (1979) and the results of some empirical studies (e.g. Ito, 2009; Behjat \& Sadighi, 2010) low proficiency in foreign language impedes the positive transfer of writing skills from L1 to L2, while, as Ito's study (2009) showed, this impediment does not happen for intermediate and advanced EFL learners. Hence, this study took the middle way between intermediate and advanced levels. Second, language learners at upper-intermediate level, especially those who are majoring in the English language are well familiar with writing argumentative compositions in English. The last reason for choosing upper- intermediate level was the availability of students at this level of proficiency in the context of the study.

\subsection{Instruments and Materials}

Two testing instruments were employed to collect the relevant data for this study, including one proficiency (placement) test and two writing exams.

The first testing instrument is Oxford Placement Test 1 (2004). This test was administered to determine the language proficiency level of the students. Those test takers who scored between 135 and 149 (OPT Band 5) out of 200 on this test were considered as "Upper- intermediate - competent user" (Allan, 2004).

The second testing instrument includes two composition tasks, one in the first language (Persian) and the other one in the foreign language (English). In order for the subjects to have equal planning time for each composition and to avoid interference, two different argumentative topics were given to the subjects, one to write on in Persian and the other to write on in English. The reason for choosing argumentative topics is that "It is common in the academic disciplines and it is sensitive to task, audience, and community, and it is particularly difficult for non-native speakers" (Johns, 1993, p. 76). In addition, as mentioned in the Review of Literature, since in a study by Zia Houseini and Derakhshan (2006) the cross-linguistic transfer of writing abilities in argumentative compositions was only moderately significant, further research is needed to confirm the significance of such a transfer. The English topic and prompt were taken from "Task 2 of Academic Writing Module of IELTS Past Papers" out of the book Cambridge IELTS 5 (2006, p. 76). The Persian topic and prompt were the translated versions of another topic and its related instruction of the same type of task out of the book Cambridge IELTS 7 (2009, p. 31). The topics were randomly chosen from the past papers of the same international examination (IELTS Past Papers) so that they both have the same level of difficulty.

\subsection{Procedures for Data Collection and Data Analysis}

To collect the relevant data, two testing sessions were administered within two sessions. During the first session, the Oxford Placement Test was administered which lasted up to 60 minutes and consisted of 200 multiple-choice questions. It was followed, after a two-week interval, by the second session where the writing tests were administered.

During the second session of data collection, the 50 upper intermediate students who had already been selected through the OPT were asked to write two argumentative compositions on given topics, one in Persian and one in English. Therefore, the participants were instructed to write at least 250 words in about 40 minutes for each composition, and then the compositions were collected at the end of each set time. The participants were not allowed to use dictionary or any other additional sources of information such as grammar or reference books. In order to counterbalance the negative effect of the participants' tiredness on the results of the tests, half of the participants were given the L1 topic to write on at first and then the L2 topic, while the other half were first given the L2 topic and then the L1 topic. There was also a 10-minute interval between the two compositions.

Then, the compositions were evaluated based on ESL Composition Profile (Jacobs et al., 1981, p. 91) for analytical scoring. The rationale behind using this scale is that it is a valid rubric for assessing writing since its validity related issues, including face validity, content validity, concurrent validity, and construct validity have already been reported by Jacobs et al. (1981).

Moreover, the efficacy of Jacobs et al.'s (1981) framework has been investigated by Brown and Baily (1984), and it is found to be a sound practice in assessing writing performance.

Based on ESL Composition Profile (1981), compositions were rated through holistic judgments for 21 analytical subcomponents of five major components of writing including:

1) Content: knowledge of subject, range of substance, development of thesis, and relevance to assigned topic

2) Organization: fluency of expression, clarity of stated/supported ideas, succinctness, quality of organization, logical sequence of ideas, and cohesion

3) Vocabulary: range of vocabularies, effectiveness of word/idiom choice and usage, word form mastery, and register appropriateness

4) Language use: effectiveness and complexity of constructions, and grammatical correctness (agreement, tense, number, word order/function, articles, pronouns, prepositions)

5) Mechanics: spelling, punctuation, capitalization, paragraphing, and handwriting

However, since capitalization is not an issue in Persian texts, it is not taken into consideration in evaluating Persian compositions. 
These five major components of writing (writing sub-skills) are differently weighed in assessing the compositions. Out of 100 as the aggregate score, a range of, 13-30 points is assigned to the "content," 7-20 to the "organization," 7-20 to the "vocabulary," 5-25 to the "language use," and 2-5 to the "mechanics."

It is worth mentioning that before evaluating the compositions, a briefing session was held to explain the scoring procedure to the raters and the issue of inter-rater reliability was dealt with subsequently. After examining the inter-rater reliability and evaluating all compositions, the mean scores were calculated for Persian and English compositions. The total score for each composition was the average of two independent ratings. Then, using SPSS 16, the Pearson productmoment correlation analysis was run to calculate the correlation coefficient between L1 and L2 compositions, and between their corresponding sub-components to test the first and the second null hypotheses respectively.

Hence, in order to investigate the first null hypothesis of this study the correlation between the mean scores (average of two independent ratings) of Persian and English compositions were calculated. If it proved to be significantly high, the first hypothesis would be rejected which would indicate the existence of a relationship between the overall writing skill of first language (Persian) and foreign language (English).

In the same way, for examining the second null hypothesis of this study, the correlations between the mean scores of each of five major components of Persian compositions and their corresponding components of English compositions were calculated. If they proved to be significantly high, the second hypothesis would be rejected which would indicate the existence of relationships between the respective writing sub-skills of first language (Persian) and foreign language (English).

\section{Results and Discussion}

\subsection{Inter-rater Reliability}

In order to ensure the homogeneity and consistency of the ratings assigned by the four raters (two raters of Persian essays and two raters of English ones), the inter-rater reliability was examined. Based on Cohen's (1988) classification of correlation strength, a correlation is considered small when $r=.10$ to .29 , medium when $r=.30$ to .49 , and large when $\mathrm{r}=.50$ to 1.00 . The inter-rater reliability indexes were high for both Persian raters $(\mathrm{r}=.832)$ and English raters $(\mathrm{r}$ $=.875$ ) which indicate a strong correlation and is therefore acceptable for a reliable writing assessment.

\subsection{Descriptive Statistics for the L1 and L2 Compositions}

Table 1 presents descriptive statistics for the L1 and L2 compositions, including the number of compositions, the mean scores, and the standard deviations.

Table 1. Descriptive Statistics of Writing Overall Scores

\begin{tabular}{llll}
\hline & $\mathrm{N}$ & Mean & Std. deviation \\
\hline L1 Composition & 50 & 83.80 & 7.149 \\
L2 Composition & 50 & 72.92 & 9.638 \\
\hline
\end{tabular}

As shown in Table 1, the mean score of Persian (L1) essays (83.80) is greater than that of English (L2) essays (72.92). Furthermore, as displayed in Table 1, the standard deviation for Persian compositions (7.149) is lower than that of English compositions (9.638).

\subsection{Correlation Analysis for the L1-L2 Essays Overall Scores}

The first research question of this study investigates the probable relationship (correlation) between Persian and English writing skills, which is measured through the compositions overall scores. Consequently, in order to test the first null hypothesis and answer the first research question, Pearson product-moment correlation was performed.

However, before reporting this correlation, the assumption underlying Pearson correlation, namely, normality of the distribution was examined. Therefore, One-Sample Kolmogorov-Smirnov Test (K-S Test) along with a Scatter plot was employed to test the normal distribution of the scores and their results indicated the normality of the distribution.

After confirming the normality of the distribution, Pearson product-moment was run to examine the correlation between the overall scores of Persian and English essays. Table 2 presents the correlation coefficient between these two variables.

Table 2. Correlation between Persian and English Essays

\begin{tabular}{lll}
\hline & L2 essay \\
\hline \multirow{3}{*}{ L1 essay } & Pearson correlation & $.645^{* *}$ \\
& Sig. (2-tailed) & .000 \\
$\mathrm{~N}$ & 50 \\
\hline
\end{tabular}

Note. ${ }^{* *}$. Correlation is significant at the 0.01 level (2-tailed). 
As can be seen in Table 2, the correlation coefficient between Persian and English essays is 0.645, which is significant at the 0.01 level of probability. This finding rejects the first null hypothesis, and suggests that there is a significant correlation between the first language and the foreign language overall writing skills of Iranian upper-intermediate language learners in Iran.

\subsection{Descriptive Statistics for the L1 and L2 Writing Sub-skills}

Table 3 presents descriptive statistics for the five writing sub-components (sub-skills) of content, organization, vocabulary, language use, and mechanics in the L1 and L2. This table includes related information about the number of compositions, the mean scores of each of the sub-skills, and their standard deviations.

Table 3. Descriptive Statistics for Writing Sub-skills

\begin{tabular}{llll}
\hline Sub-skills & $\mathrm{N}$ & Mean & Std. deviation \\
\hline L1 content & 50 & 24.52 & 2.375 \\
L2 content & 50 & 20.96 & 3.410 \\
L1 organization & 50 & 16.84 & 1.448 \\
L2 organization & 50 & 14.68 & 1.911 \\
L1 vocabulary & 50 & 17.32 & 2.015 \\
L2 vocabulary & 50 & 15.12 & 2.256 \\
L1 language use & 50 & 21.44 & 2.251 \\
L2 language use & 50 & 18.36 & 2.981 \\
L1 mechanics & 50 & 3.68 & .621 \\
L2 mechanics & 50 & 3.48 & .707 \\
\hline
\end{tabular}

As illustrated in Table 3, the mean scores for Persian sub-skills of content, organization, vocabulary, language use, and mechanics are 24.52, 16.84, 17.32, 21.44, and 3.68 respectively. The mean scores for English sub-skills of content, organization, vocabulary, language use, and mechanics are 20.96, 14.68, 15.12, 18.36, and 3.48 respectively. This demonstrates greater mean scores for all Persian writing sub-skills in comparison to their corresponding English ones. Furthermore, as shown in Table 3, the standard deviations for Persian sub-skills of content, organization, vocabulary, language use, and mechanics are 2.375, 1.448, 2.015, 2.251, and 0.621 respectively. The standard deviation for English sub-skills of content, organization, vocabulary, language use, and mechanics are 3.410, 1.911, 2.256, 2.981, and 0.707 respectively. As can be seen, the standard deviations of all Persian writing sub-skills are smaller than their corresponding English ones.

\subsection{Correlation Analysis for the L1-L2 Writing Sub-skills Scores}

The second research question of this study investigates the probable relationships (correlations) between Persian writing sub-skills (i.e. skills regarding content, organization, vocabulary, language use, and mechanics) and their corresponding English writing sub-skills, which are measured through their scores in the assigned compositions. Consequently, in order to test the second null hypothesis and answer the second research question, Pearson product-moment correlation was performed. Table 4 presents the correlation coefficients between these pairs of variables.

Table 4. Correlations between Persian and English Writing Sub-skills

\begin{tabular}{|c|c|c|c|c|c|c|c|}
\hline \multirow{2}{*}{\multicolumn{2}{|c|}{ Writing sub-skills }} & & \multicolumn{5}{|l|}{$\mathrm{L} 2$} \\
\hline & & & Content & Organization & Vocabulary & $\begin{array}{l}\text { Language } \\
\text { use }\end{array}$ & Mechanics \\
\hline \multirow{15}{*}{ L1 } & \multirow[t]{3}{*}{ Content } & $\begin{array}{l}\text { Pearson } \\
\text { correlation }\end{array}$ & $.506^{* *}$ & & & & \\
\hline & & Sig.(2-tailed) & .000 & & & & \\
\hline & & $\mathrm{N}$ & 50 & & & & \\
\hline & \multirow[t]{3}{*}{ Organization } & $\begin{array}{l}\text { Pearson } \\
\text { correlation }\end{array}$ & & $.335^{*}$ & & & \\
\hline & & Sig.(2-tailed) & & .017 & & & \\
\hline & & $\mathrm{N}$ & & 50 & & & \\
\hline & \multirow[t]{3}{*}{ Vocabulary } & $\begin{array}{l}\text { Pearson } \\
\text { correlation }\end{array}$ & & & $.620^{* *}$ & & \\
\hline & & Sig.(2-tailed) & & & .000 & & \\
\hline & & $\mathrm{N}$ & & & 50 & & \\
\hline & \multirow[t]{3}{*}{$\begin{array}{l}\text { Language } \\
\text { use }\end{array}$} & $\begin{array}{l}\text { Pearson } \\
\text { correlation }\end{array}$ & & & & $.535^{* *}$ & \\
\hline & & Sig.(2-tailed) & & & & .000 & \\
\hline & & $\mathrm{N}$ & & & & 50 & \\
\hline & \multirow[t]{3}{*}{ Mechanics } & $\begin{array}{l}\text { Pearson } \\
\text { correlation }\end{array}$ & & & & & $.543^{* *}$ \\
\hline & & Sig.(2-tailed) & & & & & .000 \\
\hline & & $\mathrm{N}$ & & & & & 50 \\
\hline
\end{tabular}

Note. ${ }^{* *}$. Correlation is significant at the 0.01 level (2-tailed), ${ }^{*}$. Correlation is significant at the 0.05 level (2-tailed). 
As illustrated in Table 4, the correlation coefficients between Persian and English writing sub-skills of content, vocabulary, language use, and mechanics are $.506, .620, .535$, and .543 respectively, which are all significant at the 0.01 level of probability. The correlation between Persian and English sub-skill of organization, however, is .335, which is significant at the 0.05 level of probability, but not at the 0.01 level of probability. These findings reject the second null hypothesis, and suggest that there is a significant relationship between Iranian upper-intermediate language learners' proficiency in some foreign language writing sub-skills (specifically, skills regarding content, vocabulary, language use, and mechanics) and their corresponding first language writing sub-skills.

\subsection{Discussion}

In order to investigate the relationship between writing skills and sub-skills in Persian and English, descriptive and correlation analysis were conducted on the composition scores written in the two languages. These compositions were evaluated based on ESL Composition Profile (Jacobs et al., 1981) by two raters for Persian essays and two raters for English ones.

Descriptive analysis of compositions revealed higher mean scores for Persian essays in comparison to English ones, which indicates that writing in English is a more challenging task for the students. However, the result was not surprising since Persian is the students' first language, while they were only at upper-intermediate level of proficiency in English (Table 1). This is also consistent with the result of a similar study by Zia Houseini and Derakhshan (2006) which displayed higher mean scores for Persian essays rather than English ones. They found a significant difference between these mean scores, which lead them to conclude the direction of transfer from Persian to English. The smaller value of standard deviation for Persian essays comparing English ones indicates a greater homogeneity between Persian essays of the current study (Table 1). The same result was also shown in a similar study by Derakhshan (1996) who found smaller standard deviation for Persian essays in comparison to English ones. In a similar way, the mean scores of all Persian writing sub-skills were higher than the mean scores of their corresponding English writing sub-skills. This might also be attributed to the participants' lower proficiency in the second language (English), and indicates that English writing sub-skills are more challenging for the EFL learners (Table 3). The values of standard deviations were also lower for all Persian writing sub-skills in comparison to their corresponding English writing sub-skills (Table 3), which suggest greater homogeneity between each of Persian writing sub-skills.

Then, in order to test the first null hypothesis, after confirming the normality of distribution of the compositions scores through a K-S test as well as a Scatter plot, correlation analysis was conducted. Hence, Pearson product moment analysis was run to examine the correlation between the overall scores of Persian and English essays. The results, based on Cohen's (1988) classification of correlation strength, showed a large correlation $(\mathrm{r}=.645, P<.01)$ (Table 2), which rejected the first null hypothesis. Thus, it suggests a significant relationship between L1 (Persian) and L2 (English) overall writing performance of upper-intermediate language learners. This finding supports the Linguistic Interdependence Hypothesis ( $\mathrm{LIH}$ ), which postulated transfer of language skills from L1 to L2 provided sufficient exposure to L2 and motivation to learn the language (Cummins, 1979), especially at high levels of L2 proficiency, which is congruent with Linguistic Threshold Hypothesis (LTH). It is also consistent with the results of similar studies investigating L1-L2 writing relationships (e.g. Arefi, 1997; Ziahouseini \& Derakhshan, 2006; Dweik \& Abu Al Hommos, 2007; Alsamadani, 2010).

Next, in order to test the second null hypothesis, the correlation coefficients between writing sub-skills of Persian and English essays were examined. Therefore, the Pearson product-moment correlation was run to the scores of each writing sub-skills in the two languages. The results showed large correlations $(p<.01)$ between four out of five investigated writing sub-skills in L1 and L2 (Table 4). The highest correlations were observed between the writing subskills of vocabulary, mechanics, language use, and content in L1 and L2 in a descending order. However, the correlation between writing sub-skill of organization in the two languages was not significant. These findings, thus, rejected the second null hypothesis and indicated that there is a significant relationship between Iranian upper-intermediate language learners' proficiency in some foreign language writing sub-skills (specifically, skills regarding content, vocabulary, language use, and mechanics) and their corresponding first language writing sub-skills. Consequently, the results confirm the transfer of these writing sub-skills between L1 and L2.These findings also support the LIH and are congruent with LTH. In other words, although Persian and English writing are very different at surface levels such as vocabulary, grammar, and so on, due to the existence of an underlying proficiency which is interdependent across languages the cognitive/academic or literacy related skills can be transferred across these two languages (Cummins, 1984). However, it is worth noting that although there are several studies that suggest cross-linguistic transfer of some writing sub-skills (e.g. Arefi, 1997), there is no other research investigating the relationship between the aforementioned sub-skills in L1 and L2 in order to be compared with the results of this study.

In conclusion, the results of this study could reject both null hypotheses and display a relationship between overall proficiency in writing skill and most writing sub-skills of first and foreign language. Therefore, it suggested the crosslinguistic transfer of writing skill and most writing sub-skills, which supports the theoretical foundation of LIH, is congruent with LTH, and corroborates the results of similar studies.

\section{Conclusions and Suggestions}

\subsection{Summary}

There is a growing body of research and theories, especially LIH, assuming a common underlying proficiency among languages, which provides the potential for the transfer of language skills between them. This cross-linguistic transfer 
facilitates language learning since it dilutes the need for re-learning the skills previously learned in another language. On the other hand, writing, as an important and grueling language skill, plays a determining role in students' academic success, especially at university level, since the students are mostly evaluated through their written products (e.g. written examinations or research papers).

In this regard, this study investigated the relationship between writing skill and sub-skills in L1 and L2, hoping that its findings with regards to the catalyzing effect of transfer in language learning open new horizons in teaching writing for all stake holders in first and foreign language teaching arena.

Hence, 50 randomly selected upper-intermediate EFL learners at BA level who were majoring in English were asked to write argumentative essays in L1 (Persian) and L2 (English). The topics were different for L1 and L2 essays, and the students had to write on them in a limited set time without any access to additional sources such as dictionary. The compositions then, were evaluated by four expert raters (two raters for L1 and two raters for L2) employing ESL Composition Profile (Jacobs et al., 1981). Using SPSS 16, Pearson product-moment correlation was performed to calculate the correlation between the overall scores of the compositions in L1 and L2.The results showed a significant correlation between the overall scores of the composition in Persian and English. This means that students who scored higher in L1 compositions, scored higher in L2 ones, and vice versa, which indicates a relationship between L1 and L2 composition scores. This attests the existence of a common underlying writing proficiency even between languages that do not share the same orthographic system (i.e. Persian and English). This finding was in line with the findings of similar research and Linguistic Interdependence Hypothesis (LIH), suggesting the cross-linguistic transfer of writing skill. Furthermore, in order to find which writing sub-skills are more apt for such a transfer, the same test (Pearson product-moment correlation) was run to examine the correlation between each of five major components (sub-skills) of compositions in the two languages. The writing sub-skills under investigation, based on the Profile, were "content," "organization," "vocabulary," "language use," and "mechanics". The results displayed significant correlations for all of them but "organization." The highest correlations were observed between sub-skills of vocabulary, and then of mechanics, language use, and content of the two languages in a descending order. This, in its own turn, determined the magnitude of transfer of each of these sub-skills.

\subsection{Pedagogical Implications}

The present research attested the cross-linguistic transfer of writing skills between first language (Persian) and foreign language (English) which entails the following pedagogical implications.

First, since there is a significant relationship between writing scores in L1 and L2, it suggests that L1 writing proficiency can be an appropriate predictor of L2 writing proficiency. This means that the students' L1 writing scores can be used as aptitude tests for L2 writing classes.

Second, since there is also cross-linguistic transfer of writing sub-skills (esp. vocabulary, mechanics, language use, and content), student's scores on these components of writing could act as diagnostic tools, both for precaution and remedy. With precautionary purposes in mind, when language teachers see weaknesses in any of the writing sub-skills in a student's L1, they would notice that the student might not still be able to utilize the facilitating effect of the transfer of that skill from L1 to L2. Therefore, for successful learning of that specific skill in L2, the student should be taught the same skill in L1 again. Similarly, and with remedial purposes in mind, when language teachers diagnose some problems with any of the writing sub-skills in L2 - in cases that L1 is the source of error - they can easily handle that problem just by holding remedial sessions on the same skill in L1.

Third, there is a difference between the correlation values of different writing sub-skills in two languages, which indicates a difference between the transfers of different sub-skills. Therefore, it could be suggested that some of these sub-skills (due to their higher correlations) have higher potential for being transferred into an L2 successfully, and consequently they call for more attention. In other words, sub-skills of vocabulary, mechanics, language use, and content (in order) should be the focus while drawing on the facilitating role of cross-linguistic transfer of writing skills.

Fourth, the findings of this study entail some implications for all stake holders in first and foreign language teaching arena such as language researchers, material developers, test designers, and decision makers in the department of education and the department of higher-education. For example, language syllabuses at school could be collaborated in a way that the order of presentation of learning materials would be the same in both L1 and L2, or even bilingual course books could be designed. In this way, the students would benefit the reinforcing effect of recycling similar skills in two languages, which in turn would pave the way for cross-linguistic transfer of these skills. In addition, teachers could raise students' awareness of the similarity and differences between the languages and consequently enhance the positive transfer as well as inhibit the negative one. It is worth mentioning that Cummins (2005) has already demonstrated the effectiveness of "teaching for cross language transfer in dual language education." He proposed complementing monolingual instructional strategies (e.g. use of the target language for large blocks of time) by bilingual instructional strategies (representing less time in both languages than monolingual instruction) that focus on teaching directly for two-way transfer across languages. Dweik and Abu Al Hommos (2007) also, according to the result of their study, suggested the integration of the instruction of first and foreign language writing skills in students' textbooks.

In conclusion, the findings of this study, in line with the results of similar studies, indicate that appropriate teaching in L1 may benefit students when they learn an L2 (or even vice versa). In other words, they suggest that first language teachers (esp. of writing) need to pay more attention to the common deep underlying writing skills in a way that they can be tapped into when learning a foreign language. Foreign language teachers should also try their best to get most of 
this underlying proficiency potentiality by drawing students attention to what they have already acquired in their first language, and to how they can apply them in a second language.

\subsection{Future Research Proposals}

Although the results of the present study displayed the relationship between the first language and foreign language writing skills, writing as an intricate cognitive skill calls for more research to dissect its various aspects while considering different intervening variables.. However, the findings of this study could shed some light on the new lines of research in this field, and pave the way for investigating the following proposals.

First, since the present research is the only study that examined the transfer of five major components of writing based on ESL Composition Profile (Jacobs et al., 1981), further research is needed to confirm its findings while considering other variables such as gender, proficiency level, and type of essay. For instance, if significant gender differences could be found in cross-linguistic transfer (e.g. of writing), it would imply that teaching both L1 and L2 (and even designing teaching materials) should be implemented rather differently for male and female language learners. In this way, each gender could be able to cope with cross-linguistic transfer and learning a foreign language in its own most efficient way. The same implications might hold true for probable differences in different levels of language proficiency or for teaching different types of essays.

Second, although this study investigated five major component of writing, based on ESL Composition Profile (Jacobs et al, 1981), future studies could even go a step further and investigate them in depth through examining transfer of each of their sub-components (see Procedures for Data Collection and Data Analysis).

Third, the current research examined the cross-linguistic transfer of writing through product-oriented approach, while further research is required to investigate the same phenomenon through process-oriented approach.

Fourth, it seems that future studies should focus on proposing innovative techniques as well as examining the degree of their efficacy in improving the enhancing effect of cross-linguistic transfer in language learning. Collaborative / integrative language classes, which have corresponding syllabuses, team-teaching by both L1and L2 language teachers, and bilingual course books are a few examples of such techniques.

At last, it is hoped that the findings and pedagogical implications of this research as well as its suggestions for future studies could supplement the growing body of research on cross-linguistic transfer and foster more interest for similar research in this area, especially in EFL contexts.

\section{References}

Agustin Llach, M. P. (2010). An overview of variables affecting lexical transfer in writing: A review study. International Journal of Linguistics, 2(1).

Allan, D. (2004). Oxford Placement Test1. Oxford: Oxford University Press.

Alsamadani, H. A. (2010). The relationship between Saudi EFL students' writing competence, L1 writing proficiency, and self-regulation. European Journal of Social Sciences, 16 (1). Retrieved July 2, 2012 from http://www.eurojournals.com/ejss_16_1_06.pdf

Arefi, M. (1997). The relationship between first and second language writing skills for Iranian students in Sydney: An application of the Interdependence Hypothesis. (Doctoral Dissertation).Nepean: University of Western Sydney. Retrieved January 18, 2011 from http://www.Irandoc.ac.ir

Behjat, F., \& Sadighi, F. (2010). Iranian English major students' L2 grammar development: Linguistic Threshold Hypothesis. The Electronic Journal for English as a Second Language, 13(4), A-6. Retrieved October 21, 2011 from http://tesl-ej.org/pdf/ej52/a6.pdf

Blackmore-Squires, S. (2010). An investigation into the use of blog as a tool to improve writing in the second language classroom. (MA dissertation). Submitted to the University of Manchester. Retrieved August 10, $2011 \mathrm{from}$ http://www.asian-efl-journal.com/Thesis/Thesis-Squires.pdf

Brown, J. D., \& Baily, K. M. (1984). A categorical instrument for scoring second language writing skills. Language Learning, 34(4), 21-42.

Cambridge IELTS 5. (2006). Cambridge: Cambridge University Press.

Cambridge IELTS 7. (2009). Cambridge: Cambridge University Press.

Carson, J. E., Carrell, P. L., Silberstein, S., Kroll, B., \& Kuehn, P. A. (1990). Reading - writing relationships in first and second language. TESOL Quarterly, 24(2), 245-266.

Cohen, J. (1988). Statistical power and analysis for the behavioral science. Hillsdale, NJ: Lawrence Erlbaum Associates.

Connor, U. (1996). Contrastive rhetoric: Cross-cultural aspects of second-language writing. New York, NY: Cambridge University Press.

Cummins, J. (1979). Linguistic interdependence and educational development of bilingual children. Review of Educational Research, 49(2), 222-251. 
Cummins, J. (1984). Bilingualism and special education: issues in assessment and pedagogy. Clevedon, Avon, England: Multilingual Matters.

Cummins, J. (1991). Interdependence of first-and second-language proficiency in bilingual children. In E. Bialystok (ed.), Language Processing in Bilingual Children. Cambridge: Cambridge University Press.

Cummins, J (2005). Teaching for cross-language transfer in dual language education: Possibilities and pitfalls. TESOL Symposium on Dual Language Education: Teaching and Learning Two Languages in the EFL Setting. Istanbul, Turkey: Bogazici University.

Derakhshan, K. (1996). Effects of first language on second language writing - A preliminary contrastive rhetoric study of Farsi \& English. Unpublished MA dissertation. Tehran: Allameh Tabatabai University. Retrieved March 15, 2011 from http://www.irandoc.ac.ir

Dweik, B. S., \& Abu Al Hommos, M. D. (2007). The effect of Arabic proficiency on the English writing of bilingualJordanian students. Retrieved from ERIC database. (ED497505)

Ito, F. (2009). Threshold to transfer writing skills from L1 to L2. Retrieved from ERIC database. (ED506378)

Jacobs, H. L., Zinkgraf, S. A., Wormuth, D. R., Hartfiel, V. F. \& Hughey, J. B. (1981). Testing ESL composition: A practical approach, Rowley, MA: Newbury House Publication.

Johns, A. M. (1993). Written argumentation for real audiences: suggestions for teacher research and classroom practice. TESOL Quarterly, 27(1), 75-90.

Joy, R. (2011). The concurrent development of spelling skills in two languages. International Electronic Journal of Elementary Education, 3(2).

Kaplan, R. B. (1966). Cultural thought patterns in intercultural education. Language Learning, 16, 1-20.

Odlin, T. (2005). Crosslinguistic influence and conceptual transfer: What are the concepts? Annual Review of Applied Linguistics, 25, 3-25.

Raimes, A. (1985). What unskilled ESL students do as they write: A classroom study of composing. TESOL Quarterly, 19, 229-258.

Sparks, R., Patton, J., Ganschow, L., \& Humbach, N. (2009). Long-term cross-linguistic transfer of skills from L1 to L2. Languge Learning, 59(1), 203-243.

Tan, B. H. (2011). Innovative writing centers and online writing labs outside North America. Asian EFL Journal, 13 (2), 391-418. Retrieved September 5, 2011 from http://www.asian-efl-journal.com/PDF/June_2011.pdf

Zamel, V. (1984). In search of the key: Research and practice in composition. In Handscombe, J., Orem, R. A., \& Taylor. B. P. (Eds.) On TESOL '83. Washington, DC: TESOL

Ziahouseini, S. M., \& Derakhshan, K. (2006). Transfer of first language of foreign language writing: A contrastive rhetoric study of English \& Farsi. Quarterly Journal of Humanities, Alzahra University, 16(58), 75-91. 